\title{
BATTERY SIMULATION TOOL FOR WORST CASE ANALYSIS AND MISSION EVALUATIONS
}

\author{
Stéphane Lefeuvre ${ }^{(1)}$, Abdossamad Benkhalfia ${ }^{(2)}$, Edouard Mosset $^{(1)}$, Maria Nestoridi $^{(3)}$, Olivier Mourra ${ }^{(3)}$ \\ (1) Saft, Space and Defence Division, rue Georges Leclanché 86060 Poitiers - France, \\ Email:stephane.lefeuvre@Saftbatteries.com,Edouard.Mosset@Saftbatteries.com \\ (2) Saft (external), rue Georges Leclanché 86060 Poitiers - France, \\ Email: Abdossamad.Benkhalfia@Saftbatteries.com \\ (3) ESA/ESTEC, Keplerlaan 1, Postbox 299, 2200 A G Noordwijk - The Netherland, \\ Email: Olivier.Mourra@esa.int, Maria.Nestoridi@esa.int
}

\begin{abstract}
Saft recently designed, developed and qualified in the frame of Research and Development contract (GSTP-5) with the European Space Agency (ESA) three new VES16 batteries: 8S4P (4 parallel strings of 8 cells in series), 10S5P, 10S16P [1]. In order to guarantee the cells balancing (to avoid cell overcharge or over discharge during battery charge/discharge cycles), Saft introduced in parallel of each cell a simple electronic circuit called the Simplified Balancing System (SBS), which absorbs some current when a cell is close to its end of charge voltage.

The complete batteries (cells and SBS) were analysed with a proper Worst Case Analysis (WCA) to demonstrate the battery performance at the EOL of the targeted missions, including all possible effects that can influence its behaviour (cells and SBS components initial tolerances, radiation degradations, ageing and temperature effects).

Saft performed this analysis in PSpice and developed VES16 cell model and SBS models to run Monte Carlo Analysis (MCA).

The first part of this paper presents the PSpice models including their respective variable parameters at SBS and cell level. Then the second part of the paper introduces to the reader the model parameters that were chosen and identified to perform Monte Carlo Analysis simulations. The third part reflects some MCA results for a VES16 battery module. Finally the reader will see some other simulations that were performed by re-using the battery model for an another Saft battery cell type (MP XTD) for a specific space application, at high temperature.
\end{abstract}

\section{CELL \& SBS PSPICE MODELS}

In order to perform Monte Carlo Analysis, Part Stress Analysis (in nominal or fault operation) and worst case analysis, it appeared very quickly that the use of Ppsice would be an asset for a battery containing electronics. The Pspice models have been developed for the VES16 cells and SBS, based on basic Pspice models already available in the native Ppsice library (resistors, conductance blocks, Laplace blocks (for transfer functions), table blocks (for linearized functions), etc.).

\subsection{Cell model}

The first model that was developed is the VES16 cell model. This model is presented on Fig. 1. It takes into consideration:

- the Open Circuit Voltage (Voc) as a function of the Depth of Discharge (DoD) of a VES16 cell,

- the individual cell capacity,

- the cell internal resistance,

- the cell self-discharge rate,

- the cell ageing factor.

The cell is a modelled by a voltage source (generated by the E generator in block 5, representing the cell open voltage, Voc) with a current source in parallel (conductance $\mathrm{G}$ in block 3, representing the selfdischarge of the cell) and a resistance in series ( $\mathrm{Ri}$ in block 4, representing the internal cell resistance).

The open cell voltage source is generated by using a table (block 5), in which the transfer function Open circuit Voltage versus the cell Depth of Discharge (Voc vs DOD) is modelised.

The DOD of the cell is obtained by taking into account the current flowing through the cell $(\mathrm{H}$ sensor in block 6 ), the intrinsic capacity of the cell (block 2), and the initial DOD of the cell (conductance G of block 2).

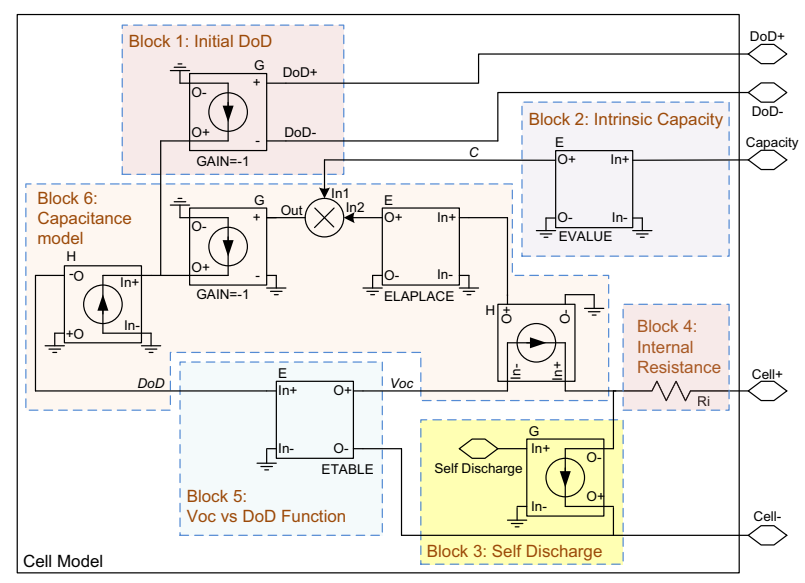

Figure 1. VES16 cell model 
On Fig. 2, the reader can see the cell linearized function Open circuit Voltage versus the cell Depth of Discharge (Voc vs DOD) that was modelled in the block 5 for the VES16 cell model. The model allows over-discharge down to the voltage reversal value and overcharge up to $5 \mathrm{~V}$ for fault battery operation.

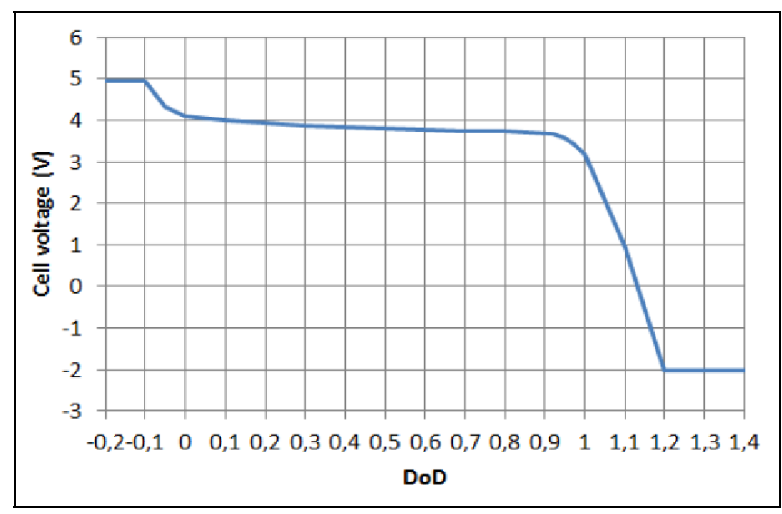

Figure 2. VOC vs DOD Transfer Function

\subsection{SBS model}

The second model that was developed is the SBS model. As previously said each battery cell is connected in parallel to a SBS.

The SBS is a simple circuitry: above a certain cell voltage value $\mathrm{U}_{0}$ (called trigger voltage threshold), the SBS absorbs some current directly proportional to the cell voltage (like a resistor called later $R_{s}$ ). Below the trigger voltage threshold, the SBS consumes a reduced leakage current. The SBS I/V characteristic is presented on Fig. 3.

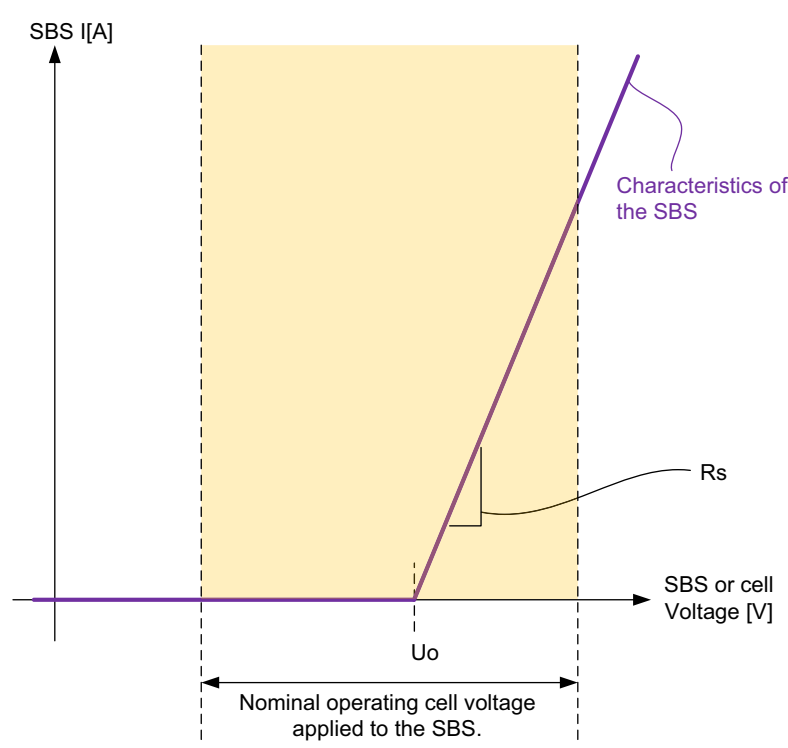

Figure 3. SBS I/V characteristics
The SBS model is presented on Fig. 4. It includes the following parameters:

- $\quad$ trigger voltage threshold, $\mathrm{U}_{0}$ (computed in block 2, and then activated by block 3 , when the cell voltage is higher than $\mathrm{U}_{0}$ )

- $\quad \mathrm{R}_{\mathrm{s}}$ (block 5)

- $\quad$ leakage resistor (block 1)

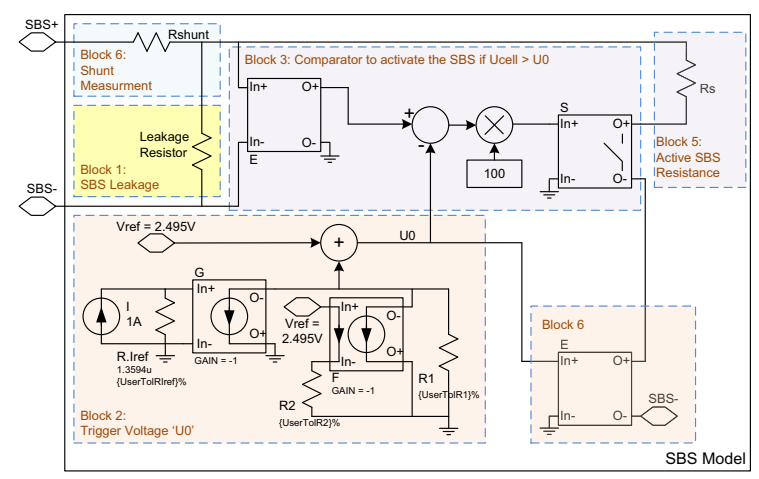

Figure 4. SBS model

\section{MODEL PARAMETERS FOR WORST CASE ANALYSIS OF VES16 BATTERY MODULES}

\subsection{Statistical data of the models parameters}

Before to run the Monte Carlo Analysis simulations in PSpice, it was essential to select which parameters will be randomly sampled in a chosen range. The following parameters were selected:

- cell capacity,

- cell internal resistance,

- $\quad$ self-discharge rate,

- $\quad$ SBS trigger voltage threshold, $\mathrm{U}_{0}$, as a combination of resistors values and internal IC parameters,

- $\quad$ SBS Leakage resistor,

- Internal SBS resistor $\left(R_{s}\right)$ when the SBS is active.

It must be also noted the study assumed the typical LEO mission parameters defined in the Tab. 1.

\begin{tabular}{|c|c|}
\hline Parameter & Value \\
\hline Mission Duration & 15 years \\
\hline TID & $15 \mathrm{krad}$ \\
\hline Min/Max Temperature & $-20^{\circ} \mathrm{C} / 60^{\circ} \mathrm{C}$ \\
\hline Orbit duration & 87 minutes \\
\hline Eclipse Duration & 27 minutes \\
\hline Discharge rate & $\mathrm{C} / 3$ \\
\hline Charge rate & $\mathrm{C} / 5$ \\
\hline
\end{tabular}

Table 1. Mission parameters 


\subsection{EOL Statistical data of the cell model}

In order to choose the cell parameters variation ranges, Saft used its internal database of VES16 Cells Acceptance Tests results (used at BOL for individual and batch acceptance), and some cells cycling tests results (tests performed to assess the ageing degradation on the cells).

For instance Fig. 5 presents the record of cell capacity measurements made during VES 16 Cell Acceptance Test.

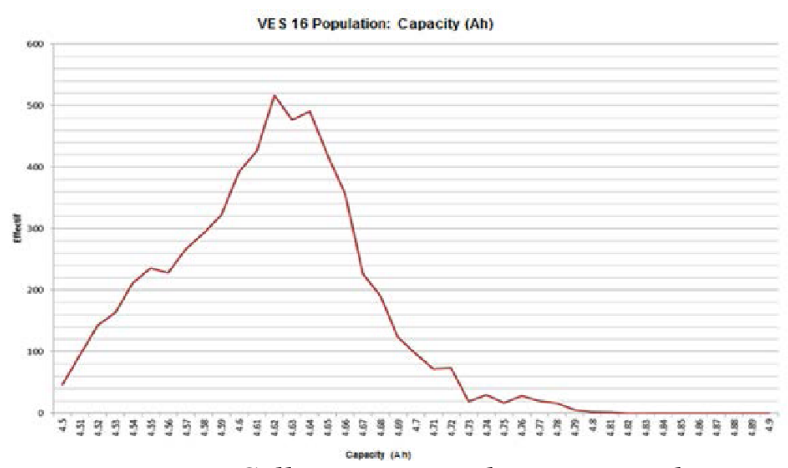

Figure 5. Cell capacity production records

Similarly, Fig. 6 and Fig. 7 present the internal resistance and the self-discharge rate of the cell measured during Cell Acceptance Tests.

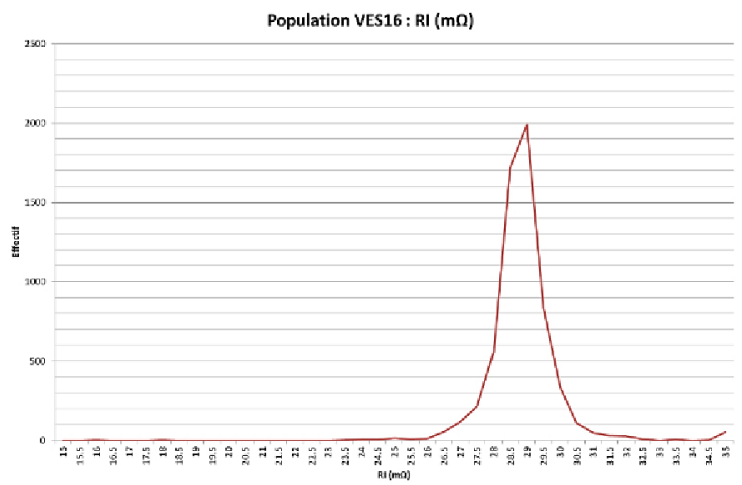

Figure 6. Internal resistance production records

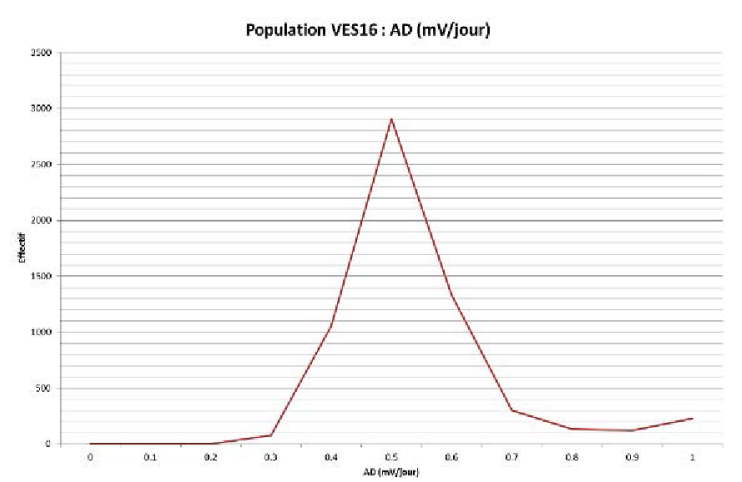

Figure 7. Self-discharge rate records

From these data, the inputs for the BoL model were computed. The distributions were approximated by a normal law. Characteristics of the distribution are given in Tab. 2.

\begin{tabular}{|c|c|c|c|}
\hline & Capacity & $\begin{array}{c}\text { Internal } \\
\text { resistance }\end{array}$ & $\begin{array}{c}\text { Self- } \\
\text { discharge } \\
\text { rate }\end{array}$ \\
\hline Min & $4.50 \mathrm{Ah}$ & $27.7 \mathrm{~m} \Omega$ & $0 \mathrm{mV} /$ day \\
\hline $\operatorname{Max}$ & $4.78 \mathrm{Ah}$ & $35.0 \mathrm{~m} \Omega$ & $1 \mathrm{mV} /$ day \\
\hline$\sigma$ & $0.06 \mathrm{Ah}$ & $0.47 \mathrm{~m} \Omega$ & $0.1 \mathrm{mV} /$ day \\
\hline
\end{tabular}

Table 2. Cell statistical parameters from manufacturing data

One can highlight that to minimise the parameters variations on the battery performances, Saft decided to select the cells to be placed in the same string. This allows minimising the differences of capacity, internal resistance and self-discharge rate of cells placed in the same string. Tab. 3 presents these differences for cells in the same strings, after cells selection.

\begin{tabular}{|l|c|c|c|}
\hline & Capacity & $\begin{array}{c}\text { Internal } \\
\text { resistance }\end{array}$ & $\begin{array}{c}\text { Self- } \\
\text { discharge } \\
\text { rate }\end{array}$ \\
\hline$\Delta$ string & $0.07 \mathrm{Ah}$ & $5 \%$ & $0.1 \mathrm{mV} /$ day \\
\hline
\end{tabular}

Table 3. String constraints

At battery model level, this matching is taken into account. For each string of the battery model, a mean value for capacity, internal resistance and self-discharge rate are randomly chosen (Gauss distribution) as per Tab. 2 and added to an individual cell specific complementary value, randomly chosen as per the values given in Tab. 3 .

In addition to these BoL statistic laws, the model includes a correction factor, to be set at the beginning of the simulation, in order to modify the cell capacity and the cell internal resistance to find the EOL variations. The correction factor is extracted from the Saft data measured at cell level (Fig. 8 and Fig. 9).

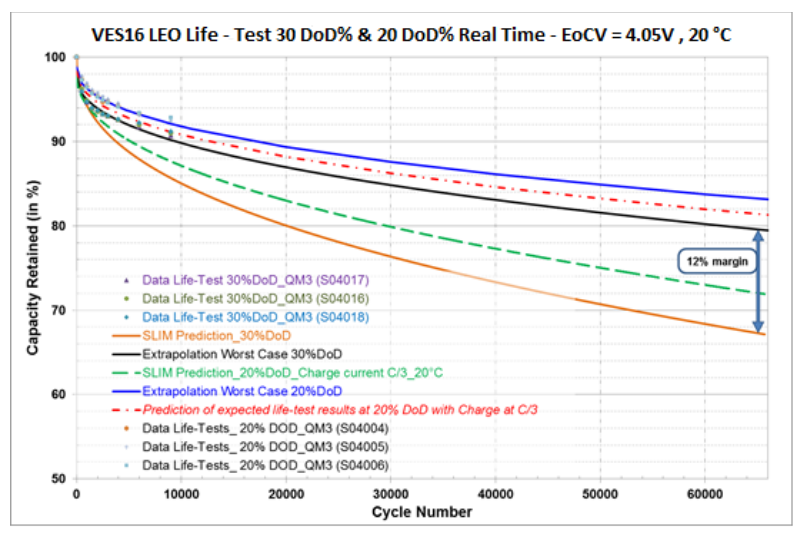

Figure 8. Capacity evolution vs number of cycles 


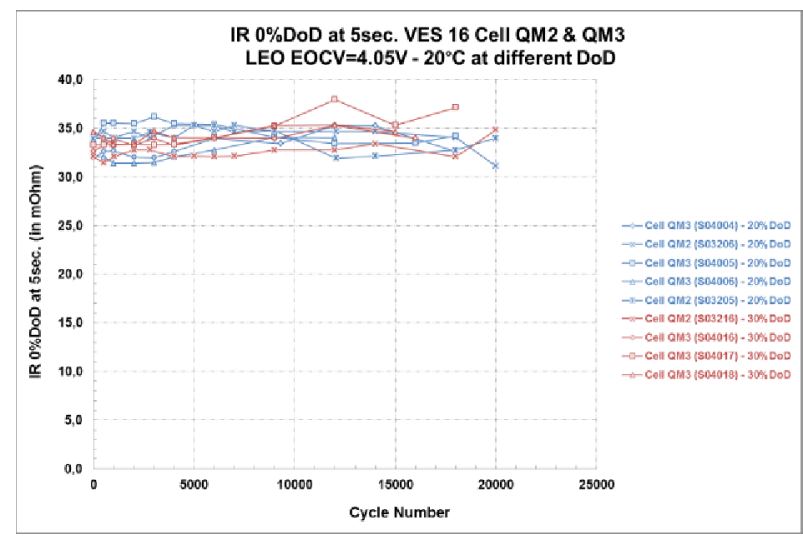

Figure 9. Cell Internal Resistance evolution vs number of cycles, at $20 \%$ DoD and $30 \%$ DoD

It must be noted that it was also observed and measured that the self-discharge rate remains constant between BOL and EOL.

\subsection{EOL Statistical data of the SBS model}

For the SBS, the SBS components manufacturer datasheet, some total dose radiation tests results and the SBS screening tests results (post assembly) helped to find the boundaries of the SBS parameters range.

It must be noted that normal distributions were chosen for the random sampling of all parameters.

For physical resistors in the SBS schematic $\left(\mathrm{R}_{\mathrm{s}}\right.$ and resistors used to set the $\mathrm{BoL} \mathrm{U}_{0}$ value), influence of temperature and ageing were computed as per ECSS-Q-TM-30-12A. As an example, Tab. 5 presents the results for a $1 \% / 100 \mathrm{ppm}$ resistor.

\begin{tabular}{|c|c|}
\hline & Tolerance ( as $\sigma$ value) \\
\hline Initial & $0.34 \%$ \\
\hline Due to temperature & $0.149 \%$ \\
\hline Due to ageing & $0.085 \%$ \\
\hline Due to radiation & --- \\
\hline Total & $\mathbf{0 . 3 8 \%}$ \\
\hline
\end{tabular}

Table 4. Resistors statistical parameters

The leakage current induced by the SBS in stand-by mode (when inactive) has been computed from data gathered during PCBA acceptance test. Characteristic of the distribution is given in Tab. 4 and was implemented as a resistor in parallel of the SBS as described on Fig. 4.

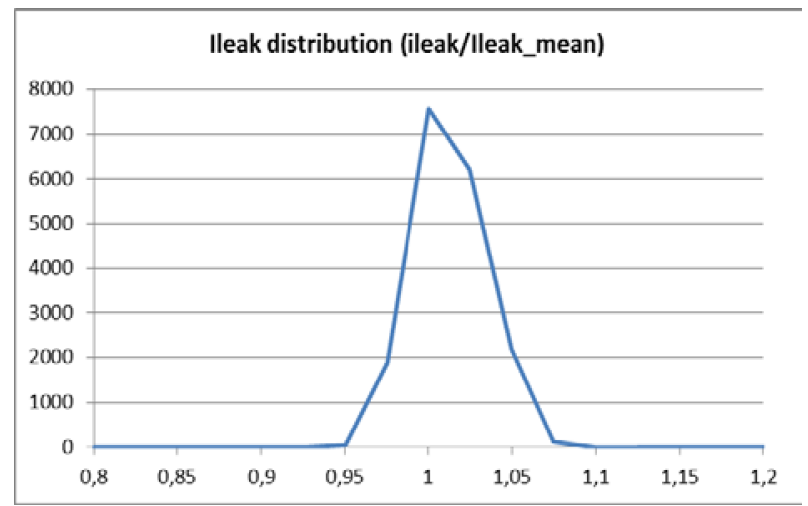

Figure 10. SBS leakage current manufacturing data

\begin{tabular}{|c|c|}
\hline & I leakage/Ileak mean \\
\hline Mean & 1 \\
\hline$\sigma$ & $2,1 \%$ \\
\hline
\end{tabular}

Table 5. SBS leakage current statistical parameters from manufacturing data

Similarly to the cell characteristics, the $\mathrm{U}_{0}$ characteristics of the SBS are matched by string. In the model, the computation of $\mathrm{U}_{0}$ is based on acceptance data presented in Fig. 11 and Tab. 6.

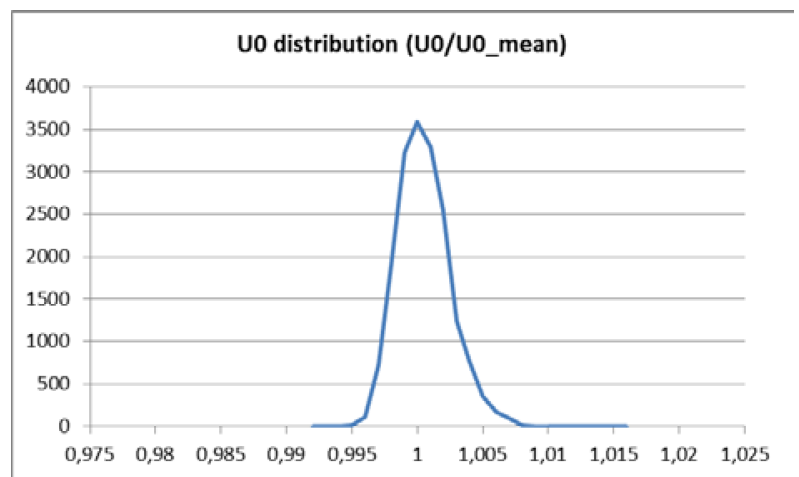

Figure 11. U threshold manufacturing data

\begin{tabular}{|c|c|}
\hline & $\mathbf{U}_{\mathbf{0}} / \mathbf{U}_{\mathbf{0}}$ mean \\
\hline Mean & 1 \\
\hline$\sigma$ & $0,2 \%$ \\
\hline$\Delta$ string & $0,3 \%$ \\
\hline
\end{tabular}

Table 6. U $U_{0}$ threshold statistical parameters from manufacturing data 
Radiations are the main contributors to the SBS ageing by modifying key internal variables that directly affect the level at which the SBS becomes active. Based on results from TID tests performed on the core component of the SBS, the impact of the radiation have been evaluated as a drift and a spread value.

The SBS model has been upgraded afterward to take into account these effects by adding resistors. For example, to take into account these variations, block 2 presented in $\$ 2.2$ has been changed to the schematic presented in Fig. 12, highlighted in red.

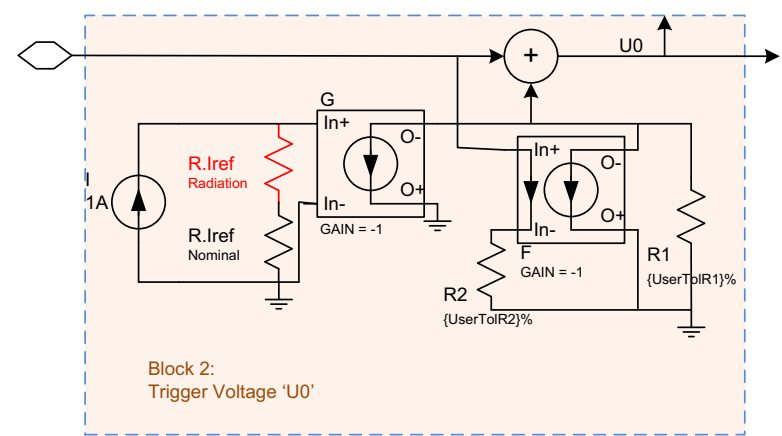

Figure 12. Modified model, with effects of radiations

\section{MONTE CARLO ANALYSIS}

Before performing the full battery model MCA, static MCA were performed to verify the variation of the SBS characteristics and verification of its specific worst case analysis.

\subsection{MCA at battery cell level}

Fig. 13 presents the statistical MCA simulation results (BOL) of the capacity performed to verify the cell model versus the Tab. 2 and Tab. 3, previously described.

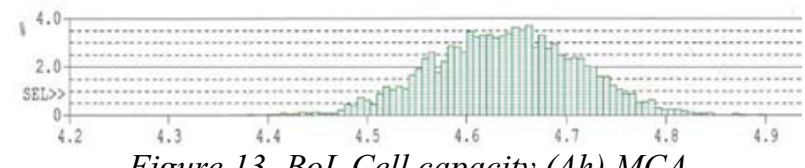

Figure 13. BoL Cell capacity (Ah) MCA

Cell Internal Resistance and self-discharge rate were verified similarly.

\subsection{MCA at SBS level}

In Fig. 14, the MCA simulation gives the SBS characteristic $I=F(V)$ using the BoL model presented in §3.3 The impact on U0 can clearly be seen, while the effect of Rs change seems lighter.

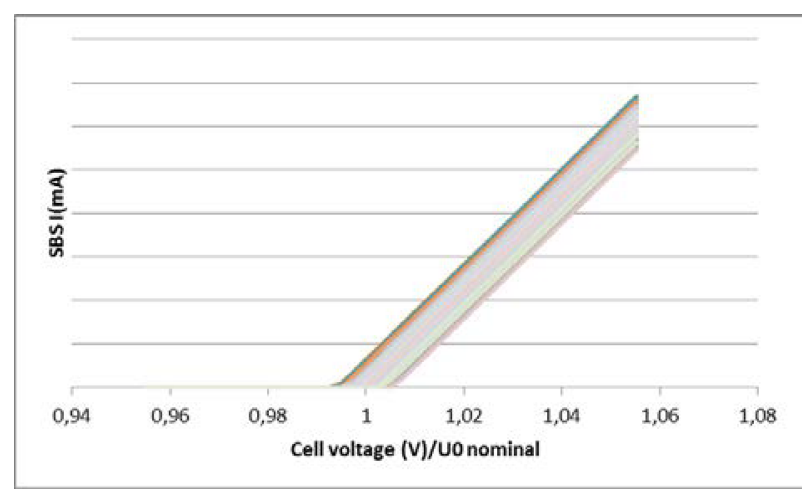

Figure 14. SBS $I=f(V)$ statistical BOL characteristics

\subsection{MCA at battery level}

Several MCA were performed in transient to analyse all the behaviours of the cells and SBS for several batteries, several LEO missions charge/discharge profiles and different satellites life times.

As an example, Fig. 15 introduces to the reader the WCA results obtained with the MCA of 800 runs, of the maximum voltage un-balance between different cells of the same battery at the BOL, for the mission having the parameters summarised in Tab. 1 .

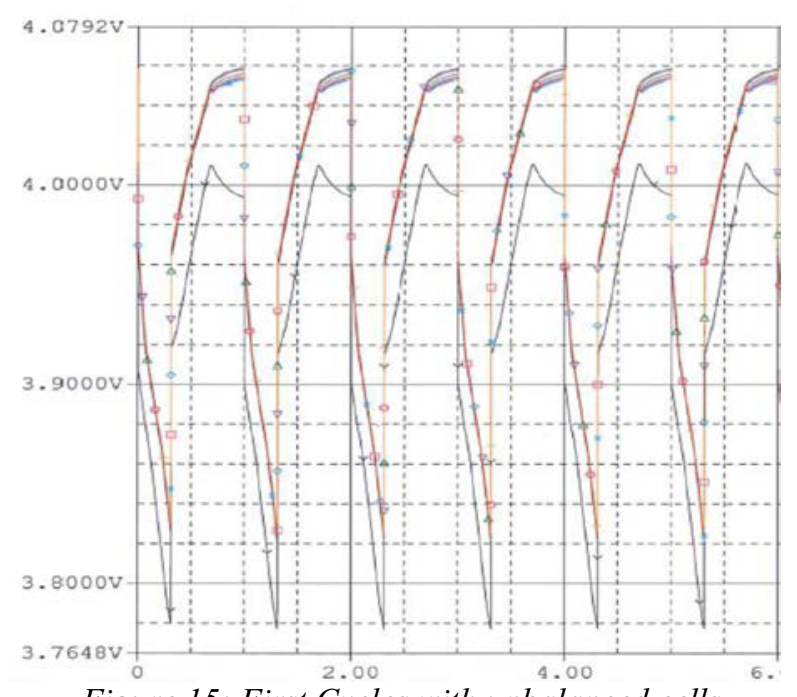

Figure 15: First Cycles with unbalanced cells

The simulation was continued until several hundred of battery cycles (charge and discharge) were reached. Fig.16 presents the maximum voltage un-balance between different cells of the same battery after 450 cycles. 


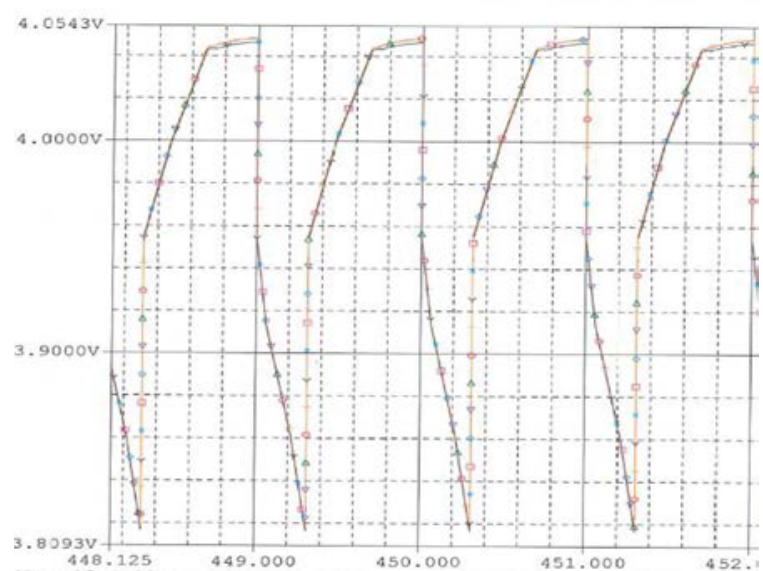

Figure 16:Balancing of the cells after 450 cycles

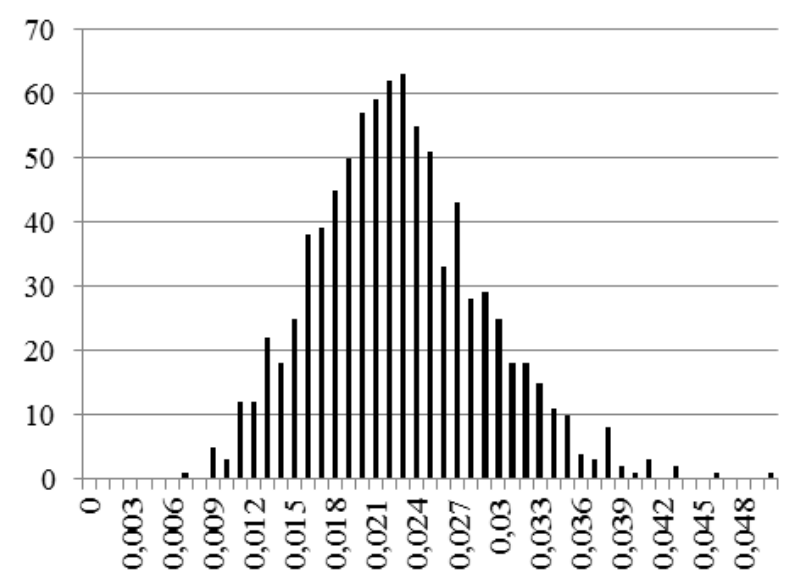

Figure 17. WCA result example of $8 S 4 P$ (800 runs) Maximum voltage string un-balance between different cells of the same battery at the EOL

From an unbalance of $50 \mathrm{mV}$ in the strings, following the 800 runs performed, the cell voltages dispersions at the End of Life (Fig. 17) were analysed.

These two graphs (Fig.16 and Fig. 17) confirm the correct operation of the SBS (no cells are overcharged or over-discharged during the mission) from an unbalanced state illustrated in Fig. 15 at the start of the simulation to a balanced state illustrated in Fig. 16 and Fig. 17.

\section{PSPICE MODEL FOR OTHER ANALYSIS}

After the development and use of the VES16 model for LEO satellite applications, it appeared that the tool could also used to define a Saft MP XTD battery maintenance charge profile for a rover during ground and cruise phases of a mission. The profile is presented in Fig. 18.

Due to particular long cruise duration and the specific high temperature, it was necessary to define a charge sequence to perform the maintenance of the battery. The sequence needed to be simple (few actions from the onboard computer), to prevent cell overcharges (over $4.2 \mathrm{~V}$ for MP XTD cells) while allowing the SBS to balance the cells.

The model, including a new MP XTD cell model, and the simulations allowed defining the most suitable charge sequence taking into account battery and user constraints. This sequence is currently being tested on a prototype battery at Saft.

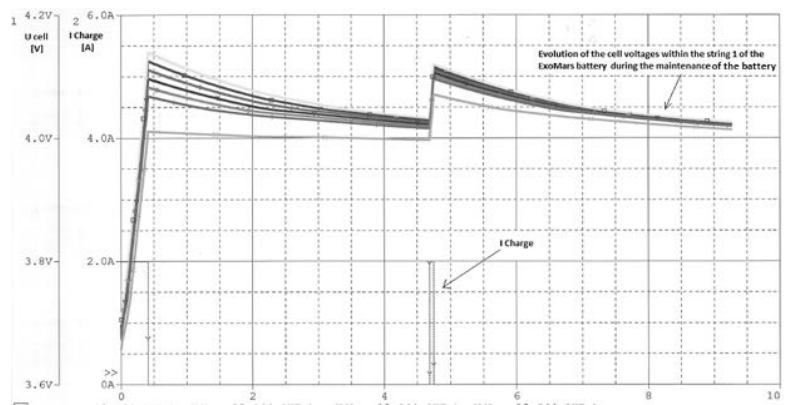

Figure 18. Maintenance profile during mission

\section{CONCLUSION AND FURTHER WORK}

Several PSpice models, including VES16 cell model and Simplified Balancing System were defined in order to model completely Saft VES16 batteries with Simplified Balancing System. First goal was to perform Monte Carlo Analysis in transient with these models to demonstrate the correct operation of the SBS at EoL.

Models proved to be adaptable enough to perform mission analysis not related to WCA, with a different cell, in this case the Saft MP XTD.

The tool is very useful to simulate different on ground scenarios (battery maintenance frequencies, recharge protocols...) as well as on orbit battery management scenarios.

The tool is currently used by the Electrical Engineer team and the next step is to improve the ease of use allowing direct use by Saft Batteries Engineers.

\section{REFERENCES}

1. Remy, S., Mosset, E., Lefeuvre, S., Nestoridi, M. (2014) VES16 Li-Ion batteries range qualification. $10^{\text {th }}$ European Space Power Conference.

2. PSpice manual, available on :

http://www.orcad.com/resources/orcad-downloads 